\title{
Robotic Radical Prostatectomy at the Egyptian National Cancer Institute: Overcoming the Challenges in the Initial Case Series
}

\author{
Ashraf Saad Zaghloul $^{1}$ (D), Ahmed Abdelbary ${ }^{1 *}$ (D) Amr Fergany $^{2}$ (D) , Hatem Aboulkassem ${ }^{1}$ (D), Waleed Mohamed Fadlalla ${ }^{1}$ (D) \\ ${ }^{1}$ Department of Surgical Oncology, National Cancer Institute, Cairo University, Cairo, Egypt; ${ }^{2}$ Consulting Urologist, Sebastian \\ River Medical Center, Florida, USA
}

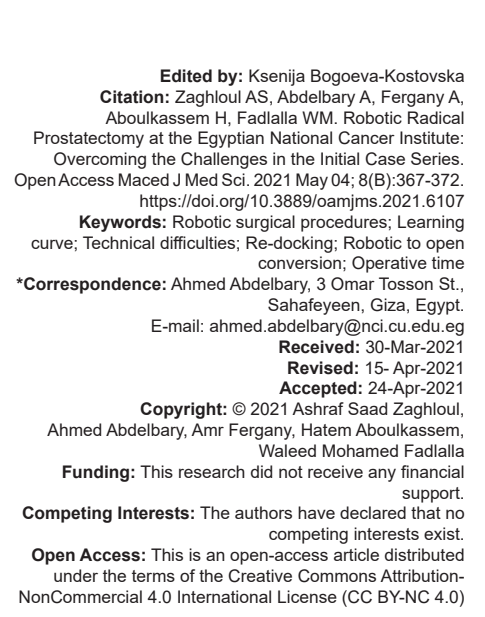

\begin{abstract}
BACKGROUND: Robotic prostatectomy is showing progressive worldwide spread owing to potential clinical benefits, but at a higher cost.

AIM: This article describes the challenges and clinical outcomes of the first group of patients undergoing robotic prostatectomy in Egypt.

DESIGN, SETTING, PARTICIPANTS: From 2017 to 2019, the data of all (55) patients undergoing robotic radica prostatectomy at the National Cancer Institute of Egypt were retrospectively analyzed.

OUTCOME EVALUATION: Short-term operative outcomes, complications, technical difficulties, pathologic data, and biochemical recurrence were reported.

RESULTS: Average blood loss was $296 \mathrm{ml}$; one patient required blood transfusion. One case required open conversion, another required re-docking of the robot. Setup time was significantly improved from an average of 27.7 $\mathrm{min}$ in the first 27 cases to an average of $17.3 \mathrm{~min}$ in the final 28 cases $(p<0.0001)$. Complications developed in $27 \%$ of our patients. Continence recovery at catheter removal, $1^{\text {st }}, 3^{\text {rd }}, 6^{\text {th }}$, and $12^{\text {th }}$ months were $32.7 \%, 50.9 \%, 65.5 \%$, $74.5 \%$, and $96 \%$, respectively.

CONCLUSIONS: Results from the first series of robotic radical prostatectomy were encouraging. Technical challenges can be overcome in a short period using a dedicated team supplemented by institutional support. Acceptable complication rate and satisfactory outcomes regarding continence and blood loss were observed.
\end{abstract}

\section{Introduction}

Prostate cancer is the most common male malignancy in the Western world. In Egypt, it is reported to be the $5^{\text {th }}$ most common solid male malignancy. The number of cases is expected to double in 2025 [1].

Surgical resection is one of the recommended treatment options for localized low/intermediate-risk patients with a considerable life expectancy, offering cancer control in most cases. Urinary continence at 12 months after prostatectomy range from 90 to $97 \%$, results for short-term continence recovery are less than spectacular with potential for improvement [2], [3].

Minimally invasive surgery encouraged urologists to adopt a laparoscopic approach to radical prostatectomy. However, laparoscopic prostatectomy and the anastomosis in the confined pelvis is a highly demanding technical procedure, with a steep learning curve which hindered propagation of the approach [4]. This fact exposes patients to complications related to the early mistakes in the learning curve.

The Da Vinci surgical robot which is a masterslave system came as an attractive option to overcome limitations and shorten the learning of standard laparoscopy In the USA, most radical prostatectomies are performed robotically [5]. Although this technology comes at a high financial cost, the momentum is still in favor of the robotic procedure despite the lack of level I evidence confirming its superiority to open surgery.

Cost is an important aspect to consider in a country with limited resources leading to considerable apprehension regarding the purchase and implementation of a robotic program in Egypt. From 2003 to 2014, no more than 1500 robotic procedures have been performed in the Arab world [6]. One Da Vinci Si system was installed at the National Cancer Institute of Egypt since 2011 which performed <200 procedures (unpublished data). In contrast, 6000 robotic procedures were performed in Italy in 2011 [6]. Economic instability was the main reason of the slow adoption of robotic surgery in Egypt, followed by limited experience with the technology. In the USA, many robotic surgeries are reimbursed by insurance companies, while in Egypt, it is not. It is evident that robotic surgery will continue to show worldwide growth, owing to consumer demand. With the awaited arrival of other systems, costs of robotic surgery may become reduced [7]. Finally, although technology 
comes at a price, successful innovation in medicine is priceless [8].

This report aims at the clinical and technical assessment of our experience with robotic prostatectomy in hopes of finding opportunities for improvement.

\section{Methods}

The data of 58 patients undergoing robotic radical prostatectomy were entered into a pre-set database, including all the relevant variables. All procedures were performed by the da Vinci Si system (Intuitive Surgical Inc., Sunnyvale, CA). This is a retrospective review of these cases.

\section{Surgical technique}

In most cases, we used the anterior antegrade approach to radical prostatectomy [9]. We used the posterior (Montsouris) approach in 9 cases [10].

\section{Study population}

The first case was performed in March 2017, and since then, 58 procedures were performed. All procedures were performed at the National Cancer Institute, Egypt, by the same surgical team. Three patients were excluded from the analysis due to incomplete data/loss to follow-up.

\section{Outcome assessment}

Continence was assessed at catheter removal, first, third, sixth, and twelfth post-operative months by Pad use, number of pads per day, and International Consultation on Incontinence Questionnaire-Short Formscore (the validated Arabic version). Continence was defined as use of no pads.

Potency was assessed using the International Index for erectile function questionnaire IIEF-5 (validated Arabic version) at similar intervals; potency was defined as the ability to achieve intercourse with or without the use of phosphodiesterase-5 inhibitors.

Oncologic outcome was assessed by reviewing the pathology report and serial PSA measurements. Requirement of adjuvant/salvage treatment was also recorded.

Complications were graded using the ClavienDindo classification [11].

Technical difficulties were reported, including re-docking, conversion to open surgery, and operative times. Setup time was defined as the time taken from skin incision to console.

\section{Statistical analysis}

Data were analyzed using SPSS Statistical version 21 (SPSS Inc., Chicago, IL). Numerical data were expressed as mean and standard deviation or median and range as appropriate. Qualitative data were expressed as frequency and percentage. A Mann-Whitney test/paired t-test was used to compare numeric variables. Tests were two-tailed, and $p \leq 0.05$ were considered statistically significant.

\section{Ethical considerations}

The study was performed according to the World Medical Association Declaration of Helsinki and the ethical standards of the National Cancer Institute, Cairo University. Written informed consent was obtained from all individuals before operation. All interventions performed were part of the routine management of the patients.

\section{Results}

\section{Baseline data}

Baseline patient characteristics are illustrated in Table 1. High-risk disease characteristics were evident among this cohort.

\section{Peri-operative parameters}

Mean blood loss was $296 \mathrm{ml}$; one patient required blood transfusion (Table 1). Bilateral nervesparing surgery was possible in $40 \%$ of patients.

\section{Complications}

Fifteen patients developed complications $(27 \%)$, of which 11 were grade III/IV Clavien-Dindo

Table 1: Baseline patient data and operative data

\begin{tabular}{ll}
\hline Variable & Mean/number (Range/Percent) \\
\hline Age & 63 years $(50-71)$ \\
BMI & $28.1(16-40)$ \\
Prostate volume & $58 \mathrm{cc}(21-240)$ \\
PSA & $21.3 \mathrm{ng} / \mathrm{dl}(5.3-109)$ \\
Gleason score (pre-operative) & \\
6 & 14 \\
$3+4$ & 27 \\
$4+3$ & 10 \\
$8,9,10$ & 7 \\
D'Amico risk group & \\
Low & $3(5.3 \%)$ \\
Intermediate & $34(57.9 \%)$ \\
High & $21(36.8 \%)$ \\
IIEF-5 score & $16(5-25)$ \\
Preoperatively potent & $26(47.3 \%)$ \\
Follow-up (months) & $17(6-36)$ \\
Length of hospital stay & 4.8 days $(2-56)$ \\
Catheterization time & 15 days $(5-70)$ \\
Blood loss & $296 \mathrm{ml}(90-2000)$ \\
Transfusion & 1 patient/55 (1.8\%) \\
\hline
\end{tabular}


complications (Table 2). There were no visceral injuries. Two cases required temporary percutaneous nephrostomy (PCN) insertion.

Table 2: Complications and technical difficulties

\begin{tabular}{ll}
\hline Complication* $^{*}$ & Number (\%) \\
\hline Wound infection & $1 / 55(1.8 \%)$ \\
Urine leak & $6 / 55(10.9 \%)$ \\
Urine leak requiring exploration & $1 / 55(1.8 \%)$ \\
Urine leak requiring PCN & $2 / 55(3.6 \%)$ \\
Ureteric injury & $2 / 55(3.6 \%)$ \\
Transfusion & $1 / 55(1.8 \%)$ \\
Urinary tract infection UTI & $1(1.8 \%)$ \\
Bladder neck stenosis & $3 / 55(5.5 \%)$ \\
Venous thromboembolism VTE & 1 \\
Lymphocele & 3 \\
Port-site hernia & 2 \\
Neuropraxia/compartment syndrome & 0 \\
Small bowel obstruction & 1 \\
Death & 0 \\
Technical difficulties & Number (\%) \\
Re-docking & $1(1.8 \%)$ \\
Conversion & $1(1.8 \%)$ \\
Device malfunction & 0 \\
Patients who developed complications & \\
$\quad$ Grade I/II & $15 / 55(27 \%)$ \\
$\quad$ Grade III/IV & 4 \\
\hline${ }^{*}$ A total of 11 patients developed grade III/IV events; however, total grade III/IV events were 15.
\end{tabular}

Three patients developed lymphoceles which required image-guided aspiration in two. Bladder neck stenosis occurred in three patients and required bladder neck incision. One patient developed port site hernia at the camera port site/specimen extraction incision 3 months postoperatively and underwent mesh hernioplasty. One patient developed left lower extremity deep vein thrombosis 6 weeks postoperatively.

Three post-operative explorations were required due to persistent urinary leak, port site bowel incarceration and exploration of left ureteric entrapment (this patient's robotic procedure was converted to open due to difficulty with urethrovesical anastomosis; he was explored 2 days later for repair of the injury).

\section{Technical difficulties}

Operative time was divided into setup and console time. We compared the first 27 cases to the last 28 cases regarding setup time. Chronologic comparison of console time was not done as the cases were performed by different surgeons. Difference in setup time was statistically significant between the first and the last cases (Figure 1) $(p<0.0001)$.

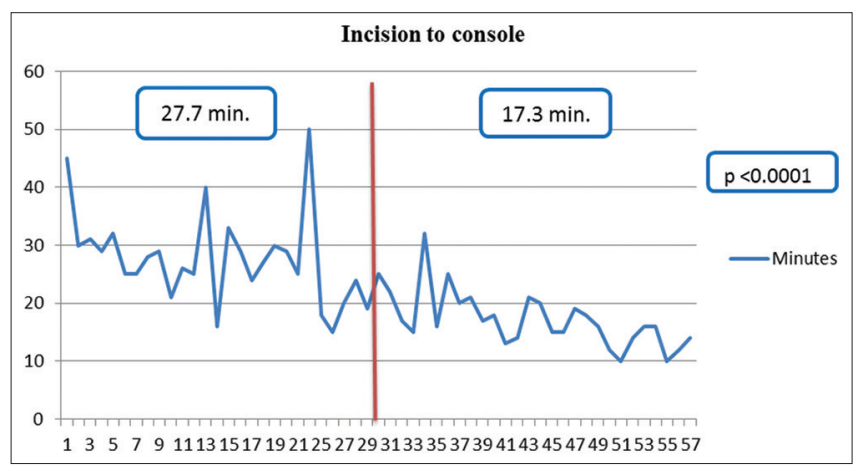

Figure 1: Setup time comparison
In one patient, undocking was required due to clashing of the camera and first robotic arm R1, the port site for the camera was changed $3 \mathrm{~cm}$ cranially, and $\mathrm{R} 1$ was changed $3 \mathrm{~cm}$ laterally, and the operation was continued robotically.

One patient required conversion to open surgery due difficulty with the urethrovesical anastomosis. This patient had a BMI of 34 , with history of transurethral resection of the prostate TURP, $70 \mathrm{cc}$ prostate, and high D'Amico risk stage.

\section{Continence}

Table 3 summarizes continence recovery. 96\% of the patients were pad free at 1 year.

Table 3: Continence and potency recovery

\begin{tabular}{ll}
\hline Parameter & Number (Percent) \\
\hline Immediate continence & $18(32.7)$ \\
Continence at $1^{\text {st }}$ month & $28(50.9)$ \\
Continence at $3^{\text {rd }}$ month & $36(65.5)$ \\
Continence at $6^{\text {th }}$ month & $41(74.5)$ \\
Continence at 1 year & $53(96)$ \\
(1) Potency recovery & $12(21.8)$ \\
(2) Potency recovery if full neurovascular bundle NVB sparing & $8 / 20(40)(p=0.03)$ \\
(3) Potency recovery if potent preoperatively & $9 / 25(36)(p=0.048)$ \\
(2) and (3) & $7 / 13(53.8)(p=0.01)$ \\
\hline${ }^{*}$ Continence defined as being pad-free. ${ }^{* *}$ Potency defined as ability to achieve intercourse with or without \\
use of PDE-5 inhibitors.
\end{tabular}

\section{Potency}

Twelve patients $(21.8 \%)$ recovered erections sufficient for intercourse. They were stratified according to pre-operative potency and intra-operative neurovascular bundle preservation in Table 3.

\section{Pathologic outcome and biochemical recurrence (BCR)}

Pathologic results are summarized in Table 4. Lymph node metastasis was present in $20 \%$ of patients who underwent pelvic lymph node dissection (10/49 cases). Lymph node dissection was performed for all high-risk and most intermediate-risk D'Amico groups, at the discretion of the operating surgeon. The most

Table 4: Pathology and adjuvant therapy

\begin{tabular}{ll}
\hline Parameter & Number (Percent) \\
\hline Pathologic T stage & 38 \\
Organ confined & 9 \\
pT3a & 6 \\
pT3b & 2 \\
pT4 & \\
Gleason score & $16(29.1 \%)$ \\
6 & $16(29.1 \%)$ \\
$7(3+4)$ & $12(21.8 \%)$ \\
$7(4+3)$ & $11(20 \%)$ \\
8 or higher & $10 / 49(20.4 \%)$ \\
Lymph node metastasis & $7(12.7 \%)$ \\
Positive margin & 5 \\
Apical & 5 \\
Bladder neck & 3 \\
Circumferential & $14(25.4 \%)$ \\
Biochemical recurrence & $16(29 \%)$ \\
Adjuvant/salvage therapy & 4 \\
Radiotherapy alone & 5 \\
Androgen deprivation therapy alone & 7 \\
Both & \\
\hline
\end{tabular}


predominant grade was Gleason 7 (50.9\%). BCR was observed in $25.4 \%$.

\section{Discussion}

This work represents the first case series of robotic radical prostatectomy in Egypt. Due to financial and logistic problems, the implementation of the program was slow. In 2017, 2018, and 2019, we performed 21, 15 , and 29 cases, respectively, in urology, representing a consistent increase in the number of cases compared to the previous years.

To our knowledge, this is the first series from an Arab country to report technical difficulties in the initial experience with robotic prostatectomy.

\section{Peri-operative parameters}

Average hospital stay was 4.8 days. We kept the patients until we were sure that they are clinically well early in our experience. Many of our patients come from remote locations and their access to well-equipped health care facilities is questionable. Catheter was removed within 12 days in $63 \%$ of patients. Finally, our practice has shifted to removing the catheter as early as on the fifth post-operative day if there are no clear contraindications, similar to most modern practices [12]. Transfusion requirements were minimal, falling within the limit of western literature [13], [14].

\section{Functional outcome}

Continence recovery was in the range of published studies even from centers of excellence [15], [16], [17], [18]. Recovery of potency is one of the most unpredictable events after radical prostatectomy as it is affected by multiple variables. Many patients had considerable pre-operative erectile dysfunction making a recovery predictably poor. Overall, $21.8 \%$ of patients recovered their potency fully. Wide resection of the neurovascular bundle was required in seven patients due to advanced disease, while full bilateral nervesparing was possible in 22 patients.

\section{Complications}

Bladder neck stenosis occurred in 5 patients $(9 \%)$. This complication is reported to range from 0.3 to $3.3 \%$ [19]. Bladder neck incision was performed in 3 patients with worsening of urinary control in two patients.

Urethrovesical anastomotic leakage is one of the common complications after radical prostatectomy, ranging from 0.3 to $15.4 \%$ [20]. Urinary leaks occurred in six patients (10.9\%). Three patients required invasive interventions, including exploration and re-anastomosis in one and bilateral PCN insertion in two patients. All three complications were from the first 20 patients in the cohort. For the subsequent 35 cases, 2 patients $(5.7 \%)$ developed increased drain output and were successfully managed by extending the catheterization period to 3 weeks.

Ureteric injury occurred in two patients (3.5\%). In one patient, the left ureter was transected during lymph node dissection. Repair was performed robotically by a psoas hitch followed by ureteric re-implantation in the dome of the bladder through a submucosal tunnel [21]. The patient experienced an uneventful post-operative course. The other patient with a history of TURP had his robotic procedure converted to open, the left ureter was entrapped within the anastomotic stitches and the patient was explored on post-operative day 2. Identification and ureteroneocystostomy were performed. Ureteric injury during robotic prostatectomy occurs in $0.06-0.9 \%$ [22], which is lower than the incidence in this series. It is important to be cognizant of this avoidable complication at certain steps of the operation; posterior bladder neck dissection, during the urethrovesical anastomosis, and the proximal portion of lymph node dissection.

Port site hernia occurred in one patient at 3 months of follow-up. Another patient developed herniation of small bowel in the immediate postoperative period. The patient presented with small bowel obstruction on Day 3. Laparoscopic assessment was performed and revealed incarcerated small bowel through the assistant port site, bowel was reduced, and the defect repaired. This complication is reported in $0.04-0.477 \%$ [22] and occurs at sites of $10 \mathrm{~mm}$ or larger trocars. Interrupted closure of specimen extraction site and using transverse incisions can potentially limit this complication [23], [24]. Although a rare occurrence, this complication was associated with extension of hospital stay to 21 days.

Lymphoceles were detected in 3 patients $(5.5 \%)$, which is within range of most published studies (0.9-30\%) [22]. In one patient, it was symptomatic, causing progressive pelvic pain and reduced bladder capacity. This was aspirated followed by injection of sclerosing agent, causing dramatic improvement.

\section{Pathologic outcome and BCR}

Seven patients had positive margins (12.7\%) which fall within the reported range (6.5-32\%) [25]. Lymph node metastasis was detected in $20.4 \%$.

BCR ranges between $8 \%$ and $40 \%$ and is a powerful surrogate for oncologic outcomes [26]. None of our patients were screen-detected and $36 \%$ were of high-risk D'Amico stage. BCR developed in 14 patients (25.4\%) until last follow-up. Mean follow-up was 17 
months (range: 6-36 months and ongoing). Longer follow-up is required to appropriately assess oncologic outcome, results of long-term follow-up will provide insight on the natural history of prostate cancer in this high-risk population.

\section{Technical difficulties}

Operative time was divided to setup/ preparation and console time. The same operating team was included in all cases to allow for improvement with experience and a dedicated program director who is an experienced uro-oncologic surgeon. To reduce the learning curve associated with console time, an experienced robotic surgeon performed the first 12 surgeries. Three surgeons with good exposure to open prostatectomy visited centers of excellence to acquire the surgical know-how, including simulator training, and attempt to bypass potential early mistakes.

Setup time was reduced from an average of $27.7 \mathrm{~min}$ in the first 27 cases to $17.3 \mathrm{~min}(\mathrm{p}<0.0001)$ in the last cases.

We modified our technique for assistant port placement; assistant port was liable to arm collision and poor access to the field in some steps of the operation, especially during access to the pelvic floor on the left side. After the first 13 cases, we decided to place the assistant port after docking is complete to identify the most ergonomic site for the port. A second $5 \mathrm{~mm}$ port could be utilized in difficult cases, in a position between the camera port and the right working port. We only needed an additional assistant port in five cases, usually for cranial traction on the colon and the bladder in fatty patients.

The rate of intra-operative conversion to open surgery ranges from 0.9 to $5 \%$ [27], [28]. According to literature, predictors of conversion were obesity, presence of adhesions, and early learning curve [23]. Only one patient in this study required conversion; this patient had a BMI of 34, history of TURP, $70 \mathrm{cc}$ prostate, and high D'Amico risk stage. This highlights the importance of proper patient selection, tackling challenging cases only when the early phase of the learning curve has been completed. We did not encounter device malfunction in our series.

In our experience, we felt that using the "Montsouris approach" [11] had a profound impact on facilitating bladder neck dissection, which can be confusing in the early experience. Using the $30^{\circ}$ camera also helped provide a better vantage point [29].

Egypt, a developing nation with significant economic constraints, has purchased and adopted robotic surgery through its only system at the National Cancer Institute. Experience with the first series of radical prostatectomy in a robot naive center proved that satisfactory clinical results in terms of minimal blood loss, early recovery, and return of urinary control, can be achieved. Technical difficulties with adopting this technology can be overcome as well, using a dedicated team supplemented by institutional support and international proctoring. A health economic analysis is recommended to evaluate the cost-benefit of the robot and the feasibility of continuing the service.

\section{Declarations}

\section{Ethics approval and consent to participate}

Written informed consent was obtained from all individuals before operation. All interventions performed were part of the routine management of the patients.

\section{Data availability}

Data are available upon request.

\section{Authors' Contributions}

ASZ: Project development, Program director, Primary surgeon, manuscript revision. AA: Protocol writing, data collection, manuscript writing. AF: Primary surgeon, International Proctor, manuscript revision. HA: Project development, manuscript revision. WMF: Protocol writing, data collection, manuscript revision.

\section{References}

1. Ibrahim AS, Khaled HM, Mikhail NN, Baraka H, Kamel H. Cancer incidence in Egypt: Results of the national populationbased cancer registry program. J Cancer Epidemiol. 2014;2014:437971. https://doi.org/10.1155/2014/437971 PMid:25328522

2. Gretzer MB, Trock BJ, Han M, Walsh PC. A critical analysis of the interpretation of biochemical failure in surgically treated patients using the American society for therapeutic radiation and oncology criteria. J Urol. 2002;168(4):1419-22. https://doi. org/10.1016/s0022-5347(05)64464-3

PMid:12352408

3. Bianco FJ, Scardino PT, Eastham JA. Radical prostatectomy: Long-term cancer control and recovery of sexual and urinary function ("trifecta"). Urology. 2005;66 Suppl 5:83-94. https://doi. org/10.1016/j.urology.2005.12.053

PMid:16194712

4. Cathelineau X, Arroyo C, Rozet F, Baumert H, Vallancien G. Laparoscopic radical prostatectomy: The new gold standard? Curr Urol Rep. 2004;5(2):108-14. https://doi.org/10.1007/ s11934-004-0022-x PMid:15028202

5. Kolata G. Results Unproven, Robot Surgery Wins Converts, New York Times; 2010. p. A1. 
6. Elawdy MM. Robotic surgery: A mini-review from a middle eastern perspective. Ely J Uro. 2017;1(1):103.

7. Zargar-Shoshtari K, Murphy DG, Zargar H. Re: Robot-assisted laparoscopic prostatectomy versus open radical retropubic prostatectomy: Early outcomes from a randomised controlled phase 3 study. Eur Urol. 2017;71(1):140-1. https://doi.org/10.1016/j. eururo.2016.09.016

PMid:27641790

8. Matanes E, Boulus S, Lowenstein L. The implementation of robotic surgery in Israel. Isr Med Assoc J. 2015;17(9):563-6. PMid:26625547

9. Menon M, Tewari A, Peabody JO, Shrivastava A, Kaul S, Bhandari A, et al. Vattikuti Institute prostatectomy, a technique of robotic radical prostatectomy for management of localized carcinoma of the prostate: Experience of over 1100 cases. Urol Clin North Am. 2004;31(4):701-17. https://doi.org/10.1016/j. ucl.2004.06.011 PMid:15474597

10. Guillonneau B, Vallancien G. Laparoscopic radical prostatectomy: The Montsouris technique. J Urol. 2000;163(6):1643-9. https:// doi.org/10.1016/s0022-5347(05)67512-x PMid:10799152

11. Dindo D, Demartines N, Clavien PA. Classification of surgical complications: A new proposal with evaluation in a cohort of 6336 patients and results of a survey. Ann Surg. 2004;240(2):205-13. https://doi.org/10.1097/01.sla.0000133083.54934.ae PMid: 15273542

12. Gratzke C, Dovey Z, Novara G, Geurts N, De Groote R, Schatteman $\mathrm{P}$, et al. Early catheter removal after robot-assisted radical prostatectomy: Surgical technique and outcomes for the Aalst technique (ECaRemA Study). Eur Urol. 2016;69(5):91723. https://doi.org/10.1016/j.eururo.2015.09.052 PMid:26578444

13. Korets R, Weinberg AC, Alberts BD, Woldu SL, Mann MJ, Badani KK. Utilization and timing of blood transfusions following open and robot-assisted radical prostatectomy. J Endourol. 2014;28(12):1418-23. https://doi.org/10.1089/end.2014.0225 PMid:25333318

14. Agarwal PK, Sammon J, Bhandari A, Dabaja A, Diaz M, Dusik-Fenton $S$, et al. Safety profile of robot-assisted radical prostatectomy: A standardized report of complications in 3317 patients. Eur Urol. 2011;59(5):684-98. https://doi.org/10.1016/j. eururo.2011.01.045

PMid:21324583

15. Reeves F, Preece P, Kapoor J, Everaerts W, Murphy DG, Corcoran NM, et al. Preservation of the neurovascular bundles is associated with improved time to continence after radical prostatectomy but not long-term continence rates: Results of a systematic review and meta-analysis. Eur Urol. 2015;68(4):692704. https://doi.org/10.1016/j.eururo.2014.10.020 PMid:25454614

16. Li $\mathrm{X}$, Zhang $\mathrm{H}$, Jia Z, Wang $\mathrm{Y}$, Song $\mathrm{Y}$, Liao L, et al. Urinary continence outcomes of four years of follow-up and predictors of early and late urinary continence in patients undergoing robot-assisted radical prostatectomy. BMC Urol. 2020;20(1):29. https://doi.org/10.1186/s12894-020-00601-w PMid:32188426

17. Xylinas E, Durand X, Ploussard G, Campeggi A, Allory $Y$, Vordos $\mathrm{D}$, et al. Evaluation of combined oncologic and functional outcomes after robotic-assisted laparoscopic extraperitoneal radical prostatectomy: Trifecta rate of achieving continence, potency and cancer control. Urol Oncol. 2013;31(1):99-103. https://doi.org/10.1016/s1569-9056(11)60873-7 PMid:21719321

18. Ficarra V, Novara G, Rosen RC, Artibani W, Carroll PR,
Costello A, et al. Systematic review and meta-analysis of studies reporting urinary continence recovery after robot-assisted radical prostatectomy. Eur Urol. 2012;62(3):405-17. https://doi. org/10.1016/j.eururo.2012.05.045

PMid:22749852

19. Brede $\mathrm{C}$, Angermeier $\mathrm{K}$, Wood H. Continence outcomes after treatment of recalcitrant postprostatectomy bladder neck contracture and review of the literature. Urology. 2014;83(3):64852. https://doi.org/10.1016/j.urology.2013.10.042 PMid:24365088

20. Tyritzis SI, Katafigiotis I, Constantinides CA. All you need to know about urethrovesical anastomotic urinary leakage following radical prostatectomy. J Urol. 2012;188(2):369-76. https://doi.org/10.1016/j.juro.2012.03.126 PMid:22698622

21. Politano VA, Leadbetter WF. An operative technique for the correction of vesicoureteral reflux. J Urol. 1958;79(6):932-41. https://doi.org/10.1016/s0022-5347(17)66369-9 PMid:13539988

22. Pucheril D, Campbell L, Bauer RM, Montorsi F, Sammon JD, Schlomm T. A clinician's guide to avoiding and managing common complications during and after robot-assisted laparoscopic radical prostatectomy. Eur Urol Focus. 2016;2(1):30-48. https:// doi.org/10.1016/j.euf.2016.03.013

PMid:28723448

23. Coelho RF, Palmer KJ, Rocco B, Moniz RR, Chauhan S, Orvieto MA, et al. Early complication rates in a single-surgeon series of 2500 robotic-assisted radical prostatectomies: Report applying a standardized grading system. Eur Urol. 2010;57(6):945-52. https://doi.org/10.1016/j.eururo.2010.02.001 PMid:20181424

24. Beck S, Skarecky D, Osann K, Juarez R, Ahlering TE. Transverse versus vertical camera port incision in robotic radical prostatectomy: Effect on incisional hernias and cosmesis. Urology. 2011;78(3):586-90. https://doi.org/10.1016/j. urology.2011.03.067

PMid:21741689

25. Novara G, Ficarra V, Mocellin S, Ahlering TE, Carroll PR, Graefen $\mathrm{M}$, et al. Systematic review and meta-analysis of studies reporting oncologic outcome after robot-assisted radical prostatectomy. Eur Urol. 2012;62(3):382-404. https://doi. org/10.1016/j.eururo.2012.11.026 PMid:22749851

26. Artibani W, Porcaro AB, De Marco V, Cerruto MA, Siracusano S Management of biochemical recurrence after primary curative treatment for prostate cancer: A review. Urol Int. 2018;100(3):251-62. https://doi.org/10.1159/000481438 PMid:29161715

27. Bentas $\mathrm{W}$, Wolfram M, Jones J, Brautigam R, Kramer W, Binder J. Robotic technology and the translation of open radical prostatectomy to laparoscopy: The early Frankfurt experience with robotic radical prostatectomy and one year follow-up. Eur Urol. 2003;44(2):175-81. https://doi.org/10.1016/ s0302-2838(03)00256-2

PMid: 12875935

28. Weiner AB, Murthy $P$, Richards KA, Patel SG, Eggener SE. Population based analysis of incidence and predictors of open conversion during minimally invasive radical prostatectomy. J Urol. 2015;193(3):826-31. https://doi.org/10.1016/j.juro.2014.09.113 PMid:25632850

29. Skarecky DW. Robotic-assisted radical prostatectomy after the first decade: Surgical evolution or new paradigm. ISRN Urol. 2013;2013:157379. https://doi.org/10.1155/2013/157379 PMid:23691367 